ANTIMICROBIAL PROPERTIES OF BREAST MILK.

L.Gothe Cfor,$S$.Ahlstedt, R.Bronnestam, B.Carlsson, I,A. Hanson, B.Johansson, S. Karkl und,J.Winber Unirersities of Umea, Goteborg and Lund. Since neonatal gramnegative infections seem to increase at the same time as breastfeeding diminishes, the role of breset milk in the newborns defence systems needs evalnation. We have studied the presence of antimicrobial factors in colostrum and breast milk-specific( $E_{\text {.coli antibo }}$ dies of the classes $I_{g A}, I_{g M}$ and $I_{g G}$ ) and unspecific (lactoperoxidase, lactoferrin and complement). l.Lactoperoxidase, which is present in high concentrations in cows milk, was demonstrated only in low quantities breast milk. This might be compensated by the high concentrations we found in the newborn's saliva. 2. Specific $E_{\text {. }}$ coli 0-antibodies of the IgA-class were demonstrated in they were not present in the serum of the mother. In contrast IgG-and IgM-E.coli antibodies were present in low concentrations in breast milk than in serum bodies pass along the GI-tract and appear in faeces with retained agglutinating capacity 3 . The relation between the maternal and infantile $E_{0}$ coli strains is studied. hether or not the specific E.coli antibodies in breas milk influence the selection of the E.coli strains colonizing the infant's bowel is under investigation.

LIPID COMPOSITION AND ABSORPTION BY LOW BIRTH WEIGHT INFANTS.

Or. D.Barltrop, Paediatric Unit.

St. Mary's Hospital Medical School, London. Increasingly, the butterfat of infant milk formulae is being replaced by mixtures of vegetable oils. In this report the absorption of lipids and calcium has been determined in six low birth weight infants fed 3 experimental filled-milk formulae differing only in their total fat content. The retention of individual fatty acids has been determined by gas 1 iquid chromotography. The absorption of fat is related to the fat content of each milk and to the composition of the constituent lipids. A marked inverse relationship between absorption and chain length of saturated fatty acids is described. Absorption of a single (C18) fatty acid is related to the degree of unsaturation. The findings are discussed in relation to the elaboration of new infant milk formulae for low birth weight infants.
HORMONAL PATTERN IN NEWBORN INFANTS FROM DIABETIC MOTHERS WITH HIGH INSULIN TREATMENT DURING PREGNANCY A.Falorn $i^{*}$, F.Mass $i-B$ enedett $j^{*}$, P.Peness** and $A$. Marini**. - * Pediatric Clinic of the University of Perugia. ** Newborn Unit of the Department of obstetric of the University of Milan.

In previous researches higher sensitivity of the alfa-cell to glucose was found in infants born to mothers affected by insulin independent diabetes compared with infants of normal mothers. Infants born to diabetic mothers, who had been treated with high doses of insulin in order to keep their blood glucose levels below 70-80mg \% during the whole pregnancy, were selected for this research. In such infants the clinical picture was normal, hyperbilirubinemia and hypocalcemia were absent and hypoglycemia was very seldom observed. Glucose metabolism. plasma insulin,glucagon and $H G H$ concentrations were determined during intravenous glucose tolerance test performed via the umbilical vein in these infants, and compared with those studied in normal newborn infants and in infants affected by erythroblastosis fetalis.

GLUCOSE IN THE NEWBORN INFANT.BLOOD CONCENTRATION, TURNOVER AND TURNOVER RATE. E.Gladtke and G.J.Stock.

The blood glucose concentration in the newborn after delivery corresponds to the mother's glucose level. During the following hours, this concentration falls to a very low level and remains there for some days.

After intravenous loading in babies a few hours old the glucose level decreases in the same manner as is always found after intravenous glucose tolerance test.

The curves after intravenous loading on the one hand as well as after delivery on the other hand show the same course.

In newborns the biokinetic data, namely elimination half life, turnover rate and turnover show a slower elimination and turnover rate and a diminished turnover compared to older children.

We therefore conclude, on account of our investigations, that the decrease of the infant's glucose curve after birth is not a question of higher glucose consumption but only of the elimination from a higher maternal glucose level to a lower newborn level in the same way as after intravenous load.

\section{INSULIN AND GLUCOSE METABOLISM}

INSULIN BIOSYNTHESIS DURING DEVELOPMENT, E. Heinze, H. Schatz, C. Nierle, E.F. Pfeiffer, Depts. of Pediatrics and Internal Medicine, Univ. of Ulm, $79 \mathrm{Ulm} /$ Donau, Germany

In adult rat islets of Langerhans glucose is an important stimulus for insulin biosynthesis and release. In contrast fetal islets secrete only small amounts of insulin when challenged acutely with glucose while the biosynthes is has not been evaluated. Therefore the incorporation of $H_{3}$ - leucine into insulin and insulin was studied in 21 -day old fetal. 5 day old and 10 day old newborn rat islets. In fe-' tal islets the incorporation of $\mathrm{H}^{3}$-leucine into insulin was enhanced by $50 \mathrm{mg} \%$ and $100 \mathrm{mg} \%$, while $300 \mathrm{mg} \%$ or the addition of glucagon was without ef fect. The biosynthesis of insulin in 5 day old efborn islets was augmented by all glucose concentrations tested, again glucagon had no effect, 10 day old newborn islets reacted similar to adult islets: glucose stimulated the incorporation of $\mathrm{H}^{3}-1$ leucine into the proinsulin and insulin peak from $50 \mathrm{mg}$ to $300 \mathrm{mg} \%$ and glucagon further enhanced this effect at the high glucose concentration.

The results suggest separate mechanisms for insulin biosynthesis and release.
GLUCAGON INFUSION IN ERYTHROBLASTOTIC INFANTS R.D.G. Milner, S.K. Chouksey and R. Assan, Universities of Manchester and Paris.

10 or $50 \mathrm{ug}$ glucagon was added to the blood preserved with acid citrate and dextrose( $A C D$ ) used for ex change transfusion (ET) of Rh-affected infants. Both doses had similar effects causing greater hyperglycemia and insulin secretion than ACD blood alone. At the end of the ET the plasma glucagon in infants receiving ACD blood was $24833 \mathrm{pg} / \mathrm{ml}$ and did not change significantly in the next 60 min. Plasma glu cagon levels in the two other groups were 1302146 and $3975327 \mathrm{pg} / \mathrm{ml}$ respectively and gle 1302146 ppeared from the circulation at $13-15 \%$ per min. for $5-10 \mathrm{~min}$ and at $0.5-1.0 \%$ per min thereafter. The range of glucose disappearance ( $\left.k_{t}\right)$ in the hour following transfusion was similar in tall groups being $0.4-2.1 \%$ per min, but for a given $k$ the infants receiving glucagon enriched blood had higher plasma glucose levels. The plasma glucose 60 min posttransfusion correlated closely and negatively with the $K_{t}$. It is concluded that glucagon protects against hypoglycemia in the first post-transfusion hour and that the plasma glucose level $60 \mathrm{~min}$ posttransfusion is a good guide to $k$. 